\title{
QUALITY ASSESSMENT OF ONLINE DISCUSSION FORUMS: CONSTRUCTION AND VALIDATION OF A SCALE THAT VALUES STUDENT PERCEPTION
}

\author{
Dr. Alessandro Silva de OLIVEIRA \\ ORCID: 0000-0001-8148-0621 \\ Department of Administration \\ Federal University of Mato Grosso do Sul \\ Chapadao do Sul - MS, BRAZIL
}

Dr. Matheus Alberto Rodrigues SILVA

ORCID: 0000-0002-5026-1079

Federal Institute of Sao Paulo Jacareí - SP, BRAZIL

Dr. Dirceu da SILVA

ORCID: 0000-0003-3267-511X

Department of Cultural Practices

Campinas State University

Campinas, BRAZIL

Dr. Richardson Coimbra BORGES

ORCID: 0000-0002-4404-2435

Department of Administration

Federal University of Mato Grosso do Sul

Paranaíba - MS, BRAZIL

Received: 03/06/2020 Accepted: 03/03/2021

\begin{abstract}
Online learning is a reality in much of the world. Among the tools available for online learning, there are Online Discussion Forums (ODF), due to their potential to promote collaborative learning. However, there is a lack in the literature about the evaluation of the forums, a gap marked by the absence of quantitative tools that make it possible to evaluate the forums from the student's perspective. In this sense, the objective of this paper was to develop and validate a Quality Perception of Online Discussion Forums (QPODF) scale. To this end, quantitative research was carried out with students of postgraduate courses lato sensu the online distance education. Exploratory factor analysis and confirmatory factor analysis was used to validate the QPODF scale. The results demonstrate that the quality of the construct perceived online discussion forums has two dimensions "Forum Structure" and "Forum Mediation." The two identified factors were shown to be consistent and accurate to measure the quality of online forums. Moreover, the theoretical approach used to compose the scale is convergent with the measurement model proposed in the paper.
\end{abstract}

Keywords: Discussion forum online, online learning, Structural Equation Modeling, collaborative learning.

\section{INTRODUCTION}

Online learning is becoming an increasingly attractive option in the field of education. In this sense, teaching and learning online tools are developed to support distance education. They are thereby resulting in the availability of new online learning tools that have enormous potential for collaborative learning (Cacheiro-Gonzalez et al., 2019; Ting, 2013; Tan, 2006). Among the educational alternatives available for 
the educations professionals can highlight the use of the Online Discussion Forums (ODF). The use of ODF encourages more in-depth analysis and critical reflection by participants (Chang, Chen and Hsu, 2011). Participants in the forums can also work alone or interacting with their peers (Alzahrani, 2017). These spaces for debates consist of environments characterized by timeless communication, with specific social locus where there is a debate of ideas, exchange of experiences, and the construction of knowledge about a particular theme (Cacheiro-Gonzalez et al., 2019; AlJeraisy et al., 2015).

In universities, ODF is a tool very utilized in the students' teaching-learning process. (Cacheiro-Gonzalez et al., 2019; Alzahrani, 2017; Aljeraisy, et al., 2015; Blackmon, 2012; Chang, Chen, \& Hsu, 2011; He, 2012; McNamara and Burton, 2009; Andresen, 2009). Due to social and collaborative environment interaction, ODF can have a positive effect on the academic achievement of students (Tan, 2017; Wei, Peng \& Chou, 2015; Jacob, 2012; Koole, et al., 2014; Xia, Fielder \& Siragusa, 2013; Shana, 2009). In general, students have been receptive to the ODF (Tan, 2017; Revill \& Terrell, 2005). However, to make the most effective ODF, many presuppositions need to be addressed. For example, present the activity goals, provide specific material, ask questions that promote reflection and discussion, and have tutors who know realize timely interventions. For this, existing literature a few parameters determining the quality about ODF (Parks-Stamm Zafonte \& Palenque, 2017; Nandi, Chang \& Balbo, 2009; McNamara \& Brown, 2008; McLoughlin \& Luca, 2000; Wozniak \& Silveira, 2004; Graham, et al., 2001;). These parameters serve as guides for the evaluation of ODF.

Cameron (2009) draws attention to the importance of discussing ways of evaluation of ODF. In the literature, evaluation methods of the ODFs can be classified into quantitative and qualitative. The quantitative approach involves simple counting procedures on the production of students. Thus, indicating a limitation of lack of content analysis, resulting in passivity on the part of students (Nunes et al., 2014; Shaul, 2007). The qualitative approach, in turn, emphasizes the particular content, using mostly rubrics (Nandi, Chang \& Balbo, 2009). But features as the central limitation time and effort that the teacher needs to undertake the evaluation (Shaul, 2007). In the same sense, there is the use of data mining techniques to generate reports (Feldman, 2007; Ellis, 2005; Dringus \& Ellis, 2005;) and the use of self-assessment mechanisms of the pairs (Lee, 2008).

As can be observed, the evaluation of an ODF can have several characteristics, such for example, a reflective summary, an online survey, peer review tasks (Tan, 2017; Vonderwell et al., 2007). Hulkari and MahlamakiKultanen (2008) suggest that an objective tool to measure learning evidenced by online discussion has not yet been developed. The absence of surveys to assess the quality of ODF on the student perspective is notorious. In this framing of quality assessment, it was noted that the students' judgment has an essential role because if there is a perception of quality, it is a sign that collaborative learning happens. Also, quality perception surveys can help educators to make improvements in the forums according to the quality principles observed in the literature (Nandi, Chang \& Balbo, 2009).

Because of the deficiency of quantitative instruments for assessing the quality of ODF, this study aims to develop and validate a Quality Perception of Online Discussion Forums (QPODF) scale, from the student's perspective. It's about a psychometric scale that will allow the evaluation of the ODF in different educational contexts. To achieve the objective of the research, a survey was carried out with the graduates of lato sensu postgraduate courses, enrolled in online distance learning.

\section{ONLINE DISCUSSION FORUMS' BRIEF BACKGROUND}

Online discussion forums are tools that allow users or students to share ideas, questions, opinions, and interact with other members in a friendly learning environment. The forums are also a mode of ComputerMediated Communication asynchronous, which allows participants to communicate with classmates in different situations (Conrad \& Dabbagh, 2018; Tan, 2017; Ting, et al., 2013). According to Biondo (2018) and Sanchez (2005), the ODF can be understood as a space for communication characterized by dialogues and messages classified according to the topic discussed. Thus, during the interactions, students can make contributions, clarify points of view, or refute ideas of the other participants.

From this perspective, the discussion forums online enable the collaborative learning process, improving reflective practice and critical thinking. In these environments, students can benefit from discussions initiated by other students and may also seek clarification with colleagues (Conrad \& Dabbagh, 2018; Tan, 2017). 
According to Revill and Terrell (2005), online discussion forums are well accepted by students and generally result in attractive, vibrant, and active discussions.

The ODF can encourage a more profound reflection than in a typical classroom situation, for are not necessary face-to-face encounters. That is because students have time to consider their responses and the posts of other students, leading to a more in-depth discussion and dialogical (AlJeraisy et al., 2015). Second Brito et al. (2011), one of the skills developed by the students in the forums, concerns the expansion of reasoning capacity and autonomy of students, that are built theme to theme. Besides that, the formation of autonomous learning groups makes forums a resource that goes beyond mediation since, due to its dynamism, its participants are not merely recipients of knowledge (Biondo, 2018; AlJeraisy et al, 2015).

According to Silva (2003), the interaction that takes place in the virtual environment provides the cocreation. Thus, online forums provide an environment for collaborative learning (Ting, 2013; Tan, 2006). Davis (2012) also noted that the forums could be used as social media too. Although these forums can provide students with social benefits, seldom instructors evaluate the posts of forum participants effectively (Nelson et al., 2005).

Previous studies have shown that the use of Online Discussion Forums can have a positive effect on the academic achievement of students. (Biondo, 2018; AlJeraisy et al., 2015; Wei Peng \& Chou, 2015; Koole et al., 2014; Jacob, 2012; Shana, 2009). From this perspective, Alghamdi (2013) concluded that the use of online discussion supplements the study in the classroom, and improves student achievement in higher education. Already AlJeraisy et al. (2015) investigated the impact of using online forums about student achievement at a private university, specifically in the Business Administration course. The authors have shown that students who participated in the forums had higher performance in exams.

\section{ASSESSMENT OF THE ONLINE DISCUSSION FORUMS}

The benefits associated with the use of Online Discussion Forums in the education sector attracted the interest of many educators (Biondo, 2018). To improve the use of this tool, several researchers have developed diverse evaluation mechanisms for the forums. However, in the literature, there are two large approaches to assess the forums - a quantitative and other qualitative. Both methods have evaluation techniques that have positive and negative points (Cacheiro-Gonzalez et al., 2019).

According to Nunes et al. (2014) and Shaul (2007), one of the primary methods of evaluation found in most online forums is the students' post count. In this method, students easily understand the measurement, and the task evaluation performed by tutors. However, there are also disadvantages, the forum topics may contain many insignificant posts that consist of little more than "agree" or "well said." Once the assessment, in this case, considers only the number of inserts, they are equally valued, regardless of content and form, and may cause dissatisfaction and lack of interest of some students. (Nunes et al., 2014; Shaul, 2007). Furthermore, as a result, the forum can become a receiver of fragmented messages and little bite articulated (Dennen, 2005). Like this, the forum as a collaborative learning tool may be underutilized (Dunlap, 2005).

Lee (2008) recommends the use of a peer evaluation system. According to the author, this method can be utilized for students to post their ideas, questions, and reflections. Then, the students can be read other messages and evaluate them according to the criteria predefined. In complement, that students can grade posted and monitor other forum participants. One benefit of this technique is that students learn while evaluating. When students are conducting the assessment, they are reading the posts of others, assimilating more content, and improving reading and writing skills (Lee, 2008). Cameron (2009) pointed out in their study that by including self-assessment activities and peer review, students become more aware of the evaluation criteria. Another approach is to form small collaborative groups of students who are responsible for one of the discussion topics (Tan, 2006; Barnes \& Geer, 2001).

There are also other forms of subjective evaluations of the forums, such as writing style, initiative, the strength of argument and originality. These variables provide a useful reference for a robust classification system called a rubric. According to Biagiotti (2005), lines are explicit schemes for classifying products or behaviors in clear categories that aim to assess learning programs, provide formative feedback to students and serves as a reference for grading. For example, Edelstein and Edwards (2002) created a forum assessment rubric that 
includes five categories: Quickly and initiative; Postage delivery; Postage relevance; Expression within the postage; and Contribution to the Community Learning. Nandi, Chang and Balbo, 2009, after a consistent literature review, identified 12 criteria to evaluate the quality of the Online Discussion Forums, divided into three factors: (1) Content, (2) Quality and interaction; (3) Objective measures. Table 1 exemplifies the evaluation rubric of stretch. Note that ratings are based on a 1 to 4 scale.

Table 1. Evaluation rubric of stretch

\begin{tabular}{llllll}
\hline Category & Criterion & $\mathbf{1 - B a d}$ & $\mathbf{2}$-Satisfactory & $\mathbf{3 - G o o d}$ & $\mathbf{4 - E x c e l l e n t}$ \\
\hline Content & Justification & $\begin{array}{l}\text { No justification } \\
\text { for the points. }\end{array}$ & $\begin{array}{l}\text { Justification based on } \\
\text { personal opinion. }\end{array}$ & $\begin{array}{l}\text { Justification using Justification using cases, } \\
\text { cases, concepts, or or } \\
\text { theories. }\end{array}$ & $\begin{array}{l}\text { concepts, or theories, } \\
\text { fostering cleardiscussion } \\
\text { of implications. }\end{array}$ \\
\hline
\end{tabular}

Note: Adapted from Nandi, Chang and Balbo (2009).

In the qualitative assessment using rubrics, the time the educator spends in the process is a considerable disadvantage (Shaul, 2007). Consider the time to work all the criteria presented by Nandi, Chang and Balbo (2009). For example, a class of 20 students can easily post 100 to 300 messages in one forum. Thus, instructor fatigue easy, and it is worthy of concern because forum management is a significant activity whiff increases the intensity, time, and efforts necessary for excellent performance (Dunlap, 2005).

An alternative to the previous methods mentioned is data mining (Data Mining). Dringus and Ellis (2005) conducted one of the first research on the use of computer systems to evaluate Online Discussion Forums. They have developed tools to aid visualization of the data produced in the forums, including dates, contribution rate, and sequences of message exchanges. Data Mining is based on pre-processing routines and algorithms that allow you to discover the patterns and results of students in the activity. According to Souza and Perry (2019) and Feldman (2007), to extract relevant information, it is necessary to define essential characteristics in the forum discussions (eg., characters, words, terms, and concepts). Souza and Perry (2019) believe that data mining has significant potential to reveal hidden information. For example, one can first extract terms from the text, then adapt or normalize them, comparing them to a list of relevant topics (concepts), extracted through a categorization.

Regardless of the type and evaluation technique employed, a vital issue in the discussion forums online is that the assessment should be fair and reliable (McNamara \& Burton, 2009). According to Kratochwill (2009), dialogical evaluation allows the teacher more than the simple monitoring of the process, but also the possibility of intervention and reflection on the action itself. Rebuilding their ways as well as enabling the learner to the reconstruction of his ideas as well.

For McNamara and Brown (2009), evaluation for the forum is a crucial indicator to show what and how students are grasping. For online discussion forums are more productive and facilitate learning, the forums need to be assessed appropriately. That means that the objective of the evaluation, the evaluation criteria, and the desired results should be established clearly and objectively. In this context, several authors conducted theoretical contributions on the subject, pointing out various quality factors for creating and managing Online Discussion Forums. Then, will be some principles for evaluating forums proposed by several researchers, are presented.

McLoughlin and Luca (2000), proposed nine categories for assessing online discussions: 1- Offer and receive assistance; 2 - Exchange resources and information; 3 - Explain and elaborate concepts; 4 -Share existing knowledge; 5 - Giving and receiving feedback; 6 - Criticizing the contributions of others; 7 - Monitor the contributions of each; 8 - Participate in collaborative tasks; 9 - Negotiate solutions to problems.

Wozniak and Silveira (2004) suggest a self-assessment in which students evaluate their contributions to the discussion. When students regularly record their perceptions of the contributions they are making to the exchange of ideas, they learn a huge amount of situations and behaviors that make productive discussion (Brookfield \& Preskill, 1999). Following this logic, Wosniak and Silveira (2004) suggest that students select three posts that demonstrate some of the following three characteristics: i) The posting was appropriate for 
the group to be able to check your consistency before the expiry of the forum. ii) The post helped foster new interactions among students. iii) The posting fulfills its role in providing feedback to the group members.

A study developed by Knowlton (2001), contributes to the literature by proposing a model of four phases of self-analysis to evaluate the contribution in the student in a discussion of online forums. In step 1 it is verified how much each answer contributes to the discussion in the forum. In the second stage, responses are made available on the forum to expand the scope of the debate. In step 3, a summary of the discussion content should be written. In the last step, it is important to write a self-analysis of your role in the discussion. In the study by Mazzolini and Maddison (2007), students identified that tutors essential must-have characteristics in the mediation of forums, such as i) Question and accompany the answers one by one; ii) Introduce new concepts or new ways of thinking about solutions; iii) Answer the questions as quickly as possible; iv) Provide feedback; v) Discuss the solutions the students of different shapes and angles.

Graham et al. (2001) conducted a study that proposed seven principles for evaluating chats and tasks in online courses. The first concerns good contact practices and teacher-student communication. In this principle, the teacher must communicate clearly and objectively with the student. The second principle, reports on the importance of encouraging, promoting cooperation and discussion among students. The third principle focuses on supporting active learning. It happens through the development and presentation of projects and academic papers. The fourth principle of emphasis on good practice feedback, which should be fast, informative, and/or motivational. The fifth principle highlights the need to provide appropriate deadlines for the tasks online. The sixth principle, in turn, emphatically the importance of having challenging tasks and case studies. The last principle concerns the various forms of learning that enable students to choose topics several that can be incorporated into the course guidelines online (Graham et al., 2001).

In the work of McNamara and Brown (2008), the authors proposed some principles of evaluation for virtual environments of education. Such principles are used as the benchmark for the construction of the psychometric scale of this paper, which aims to evaluate Online Discussion Forums. These principles, advocated by McNamara and Brown (2008), can also be found in other studies, and are presented in Table 2 below.

Table 2. Principles of Evaluation of Online Discussion Forums proposed for McNamara and Brown (2008)

\footnotetext{
Principles of Evaluation of Online Discussion Forums (McNamara and Brown, 2008) Other Authors

Present and explain to the students the objectives of the online discussion forum as Gaytan \& McEwen, 2007; Graham well as the learning advantages of the group. $\quad$ et al. 2001

Planning and organizing the forum with pre-structured topics to assist students in Vonderwell et al., 2007 managing the discussion.

The forum discussion topic should be directed with the help of activities and or Brooks and Jeong, 2005; Graham primary and supplementary readings, and also with reflective issues addressed in et al. 2001. the discussion.

Tutors shall appropriately moderate the arguments in the forums. Students need to Parks-Stamm Zafonte \& know that their participation in the forum is monitored and quality messages should Palenque, 2017; Klemm, 2000. be highlighted and valued.

Specific evaluation criteria should be established in the forums (e.g., quantity and Salmon, 2002; Graham et al. 2001. quality of the forum inserts, argumentation ability, correct writing, among others)
}

Note: Developed by the authors (2021)

The purpose of this literature review was to provide information about the various formats and technics of evaluation of the online discussion forums. After this review identified in the literature, the lack of quantitative tools to assess the Online Discussion Forums from the student's perspective (user). In this context, the objective of this paper was to carry out a survey to fill this gap. The following describes the procedures and methods performed work for the construction and validation of the scale the measure of the Online Discussion Forums. 


\section{METHODOLOGICAL APPROACH}

The quantitative approach is used in this research to achieve the proposed objective. Quantitative analysis is characterized by objective test theories, analyzing possible relationships between the variables studied. Usually, the variables can be measured by instruments so that the data is processed using statistical techniques and interpreted by the researcher (Creswell \& Clark, 2017).

The principles of evaluation of the Online Discussion Forums (ODF) proposed by McNamara and Brown (2008), constituted the primary theoretical basis of this studio. McNamara and Brown (2008) have developed a set of principles (parameters) and applied them in a discussion forum for law school students from Queensland University of Technology, in 2008, for two semesters. The authors concluded that the forum, to follow the principles proposed, was well accepted by the students and contributed to the creation of a collaborative learning environment. Thus, in this study, the principles were transformed and adapted into seven affirmatives, to evaluate the quality of the forums from the perspective of students.

In the next step, were consulted researchers with experience in the construction of psychometric scales to see if the scale items measure what you want to measure. Then, the questionnaire was built, being the type self-managed and consists of seven items. Was measurement the degree of agreement of respondents, it was used a Likert-type concordance scale of 10 points, where the first point corresponds to "Strongly Disagree" and the tenth point "Strongly Agree".

The survey sample was formed by a group of students who graduate broad sense the distance in various areas of a Brazilian Federal University. A filter question was used to collect the data. Thus, in this research participated only students who used the tool "Discussion Forum Online" as one of the course evaluation instruments. The questionnaire was developed in the Google Docs platform, which generated an access link. This link was sent to participants via email through the Google Docs forms shipping manager. The sample consisted of 128 respondents. This sample its type non-probabilistic for convenience.

The sample was divided into two, the first sample it is was used in the exploratory factor analysis, which included 64 respondents. According to the principles of Hair et al. (2018) and Tabachnick Fidell (2013), the authors suggest a higher sample of 50 observations for this type of statistical analysis. In the case of this study, we used the opinions of 64 students with 9 cases ratio for each variable. Likewise, the second sample of the 64 participants was used in confirmatory factor analysis. This sample also meets the recommendations of Hair et al. (2017) and Tabachnick Fidell (2013), which suggests that larger samples than 50 for tests with Structural Equation Modeling based Partial Least Square (PLS-SEM). This type of test does not require large samples and does not establish data normality assumptions (Ringle, Silva \& Bido, 2014).

For the analysis of the data was used the statistical software BioEstat 5.0, which made it possible to treat the data as mean, frequency, standard deviation, and variance. Exploratory factor analysis and confirmatory were used SPSS 20.0 and 2.0 SmartPLS M3 (Ringle, Wende and Will, 2005). The SmartPLS software was used in this paper because it caters well to a variety of restrictions on research relates to Applied Social Sciences. For example, investigations that have few data and 'exploratories models' with little theoretical support. This technic was enabling better forecasting and development of the theory (Hair, Ringle \& Sarstedt, 2011). The search results are presented below in the next session.

\section{RESULTS AND DISCUSSION}

\section{Description of the Participants}

After sending the questionnaire via Google Docs, we obtain 128 respondents in 10 days. The sample was composed of 31 women and 33 men, aged 17 to 25 years (10.9\%) of 26 and 35 years (56.3\%), 36 to 45 years $(18.8 \%)$, and above to 46 years $(14.1 \%)$. The duration of the courses carried out by respondents was 3 to 12 months $(57.8 \%)$ and 13 to 24 months (42.2\%). Also, of the total participants, $73.4 \%$, consider the ODF a good teaching-learning tool against $26.6 \%$ who disagree. 


\section{Exploratory Factor Analysis}

The first stage was the statistical test based on Exploratory Factor Analysis (CFA). At this moment, was verify the sphericity of Bartlett and Kaiser Meyer-Olkin (KMO) criterion. KMO values between 0.7 and 0.8 are considered as good (Malhotra et al., 2017). In this work, the KMO criteria are accepted because it is obtained a value of 0.84 . Already the Bartlett sphericity test assesses the extent to which the matrix of (co) variance is similar to a matrix-identity (Field, 2017). Concerning the Bartlett test, its indicator was significant at 0.000 , demonstrating that it is appropriate for the use of factor analysis.

A criterion to be observed to retain an adequate number of factors criterion is the Kaiser-Guttman and its representation of the explained total variance. In CFA, the explained variance refers to the portion of common variance, on the one factor or a set of factors, gat extracted from a given set of data (Hair et al., 2018). With the near eigenvalue 1 and total variance explained $79.78 \%$ of the data, it was found two factors from the data significative. It should be noted that the commonalities of the variables were observed. According to the literature, the commonalities should have values above 0.5 (Malhotra, 2020). The analysis of the commonalities of this research found values greater than 0.8 for all variables.

At that moment, the factor rotation method will be applied, which aims to facilitate the interpretation of the factors, since the variables analyzed often have high factor loads in more than one factor. The aim of factor rotations is, therefore, to find a simple solution and interpretable possible, in which each variable present a high load factor in a few factors, or only one (Damasio, 2012). The rotation method chosen was oblique, because, according to Field (2017), this method assumes that there is a correlation between the factors. In the method Oblimin Direct, the degree of correlation of the factors is determined by the value of a constant called Delta $(\Delta)$. The default value is zero, and this ensures that a high correlation between the factors is not permitted.

Table 3. Factor analysis based on Direct Matrix Rotated Oblimin of the Quality Perception of Online Discussion Forums.

\begin{tabular}{|c|c|c|c|}
\hline items & Variables & Factor 1 & Factor 2 \\
\hline Q1 & $\begin{array}{l}\text { During the distance course, the online discussion forums presented and made clear } \\
\text { what their goals were. }\end{array}$ & 0.881 & - \\
\hline Q2 & $\begin{array}{l}\text { The evaluation criteria (scores) of the online discussion forums were well established } \\
\text { and clear. }\end{array}$ & 0.882 & - \\
\hline Q3 & $\begin{array}{l}\text { The online discussion forums were well planned and organized with pre-structured } \\
\text { topics to assist you. }\end{array}$ & 0.887 & - \\
\hline Q4 & $\begin{array}{l}\text { The online discussion topics were directed with the help of readings or activities, as } \\
\text { well as reflective questions. }\end{array}$ & 0.803 & - \\
\hline Q5 & The tutors adequately moderated discussions in the online forums. & - & 0.847 \\
\hline Q6 & $\begin{array}{l}\text { As a participant in the online discussion forums, you felt that the tutors were } \\
\text { monitoring you. }\end{array}$ & - & 0.908 \\
\hline Q7 & $\begin{array}{l}\text { The evaluation criteria (scores) of the online discussion forums were well established } \\
\text { and clear. }\end{array}$ & - & 0.938 \\
\hline
\end{tabular}

Source: Research data.

When analyzing Table 3, it is possible to verify that the first four variables have higher factor loads in Factor 1 , these loads are greater than 0.8 giving robustness to the factor. The last three variables have a higher factor load in Factor 2, and they also have factor loads greater than 0.8. Because the factors are well defined, at that moment, a nomination of each factor will be proposed, according to their unique characteristics. Factor 1 was named the "Forum Structure" because the variables that comprise it are evaluating how the forums are planned and organized. The second factor was named the "Forum of Mediation" because it involves the educator tutorials activities with students. The formation of these factors are consistent and congruent with the theory proposed by Parks-Stamm Zafonte and Palenque, (2017), McNamara and Brown (2008), Gaytan and McEwen (2007), Vonderwell et al., (2007), Graham et al. (2001). 


\section{Confirmatory Factor Analysis}

In the step of the paper was the application of Confirmatory Factor Analysis (CFA), which aims to verify whether the data observed behave in accordance with the theory. The CFA serves as positive evidence for data validation and strengthens the theory studied. If there is no positive validation, the analysis makes it possible to identify possible problems with the data, with the theory, or with both (Malhotra, 2020; Spider \& Zambaldi, 2008).

In complement, the CFA, the Structural Equation Modeling based on the PLS-SEM Partial Least Squares performs the Confirmatory Factor Analysis (CFA). It thereby is possible the adjustment between the observed data and a hypostatized model (Hair et al. 2017). In this type of analysis technique, the factorial load of the latent construct mediation items is explicitly specified in the structural model. Then, the adjustment of this pre-specified model is examined to determine its convergent and discriminating validities (Malhotra et al., 2017; Gefen \& Straub, 2005; Straube, Boudreau \& Gefen, 2004). In the CFA the researcher must specify the number of factors/constructs that exist within the data set (Hair et al. 2018). In this study, two constructs were identified in the CFA.

Following the guidance of Hair et al. (2018), the two dimensions identified in the CFA were introduced in the structural model. Thus, the Quality Perception of Online Discussion Forums (QPODF) construct can be better understood when its variables are divided into two constructs: (1) Forum Structure and (2) Forum Mediation. In this way, the measurement model can be seen in Figure 1, which illustrates a reflective model with two first-order constructs and their indicators.

Based on Figure 1, it is possible to verify the dependence relationships between the variables (Q1, Q2 ... Q7) with the constructs. The arrows describe the impact of one construct on the other, which demonstrates the dependency relationships, the cause and the effect (Malhotra, 2020). To have an adjusted model, the variables of the Forum Structure and Forum Mediation constructs must have factorial loads (l) greater than 0.6, according to the guidance of Anderson and Gerbin (1988). When looking at Figure 1, it is possible to note that the factorial loads (l) are greater than 0.7 , indicating that the model is adjusted and fit for the other tests.

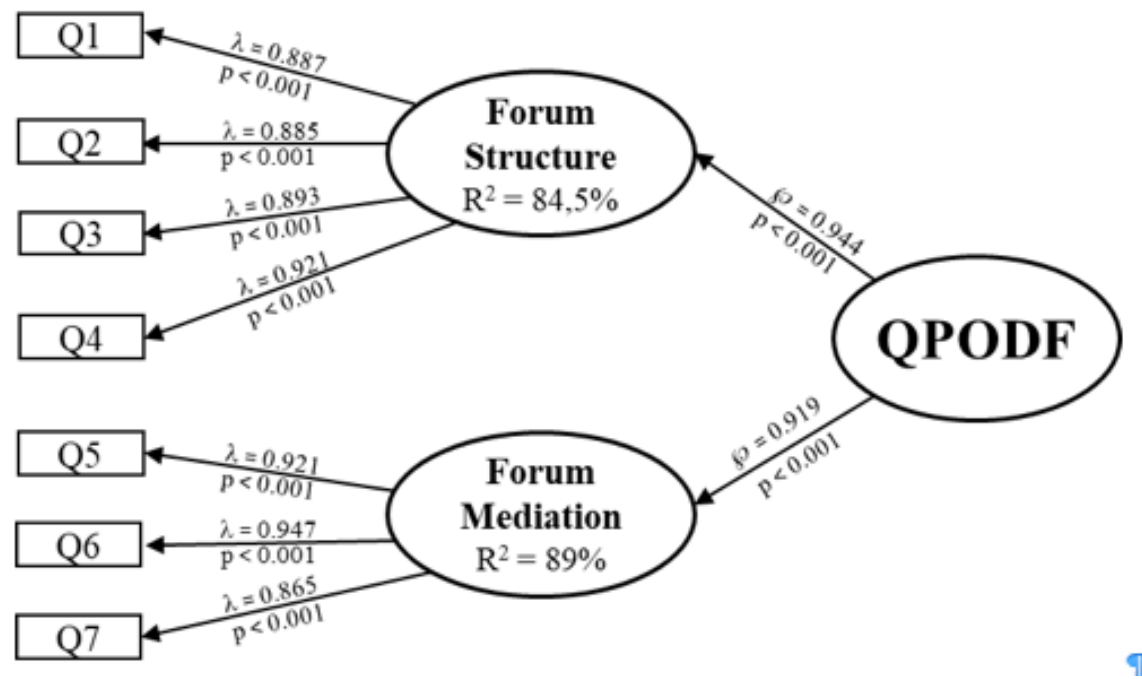

Figure 1. Measurement model and structural construct of the Quality Perception of Online Discussion Forums

Similarly, it is important to verify the robustness of the structural model, for this, the path coefficient $(\wp)$ is analyzed and also the existence of significance (a) of the values $\wp$, that represent the relationships between the constructs. The $\wp$ connecting the first-order constructs to the QPFDO construct have loads greater than 0.6 , indicating a strong relationship. Through the Bootstrapping test, it's possible to verify is loads of the coefficients of the model paths. Therefore, all relationships found in the model are significant with $a<0.001$, meeting the recommendations of Hair et al. (2018). 
The next step is to perform the Reliability and Convergent Validity test of the structural model. The Cronbach's Alpha (CA), Composite Reliability (CR), and Average Variance Extracted (AVE) are necessary to verify the reliability of the model. Cronbach's Alpha is the measure most used as a reliability indicator because it checks the correlations of a set the variable (Hair et al., 2018). According to Nunnaly (1978), the CA varies from 0 to 1 , with the range of values from 0.60 to 0.70 being considered the lower limit of acceptability. Composite Reliability is used to assess whether the sample is error-free, or whether the responses, taken as a whole, are reliable. In exploratory research, values of 0.70 and 0.90 of CC are considered satisfactory (Hair et al., 2017).

Table 4. Indicators of quality adjustment of the measurement model

\begin{tabular}{lcccc}
\hline \multicolumn{1}{c}{ Constructions } & ${ }^{\mathrm{a}} \mathbf{A V E}$ & ${ }^{\mathrm{b}} \mathbf{C R}$ & ${ }^{\mathrm{C}} \mathbf{R}^{\mathbf{2}}$ & ${ }^{\mathrm{d}} \mathbf{C A}$ \\
\hline QPODF & 0.670 & 0.930 & - & 0.920 \\
Forum Structure & 0.730 & 0.910 & 0.890 & 0.880 \\
Mediation Forum & 0.830 & 0.930 & 0.840 & 0.890 \\
\hline
\end{tabular}

Notes: This table is depicted values that attest to the quality of fit of the model. The indicator aAVE -Average Variance Extracted, bCR - Composite Reliability, $\mathrm{cR}^{2}$ - Pearson's determination coefficients, and dCA Cronbach's Alpha.

Source: Research data.

The Convergent Validity verifies the correlation between two measures of the same structural model. She confirms that the scale used is correlating with other scales of the proposed theoretical model (Malhotra et al. 2017; Pasquali, 2007). Convergent Validity can be obtained through the Average Variance Extracted (AVE). Therefore, Fornell and Larcker indicate that the AVEs must have values greater than 0.50. Thus, when the indicator is greater than 0.50 , the model converges to an acceptable result (Fornell \& Larcker, 1981). Through Table 4, it can be seen that the model in this paper met the assumptions of reliability and convergent validity suggested in the literature.

At that moment, Pearson's determination coefficients $\left(\mathrm{R}^{2}\right)$ are analyzed. The $\mathrm{R}^{2}$ represents the portion of the variance of the endogenous variables, which is explained by the measurement model. In other words, high $\mathrm{R}^{2} \mathrm{~s}$ indicate that the model is adjusted and of quality (Ringle, et al., 2015). For social and behavioral sciences, Cohen (1988) suggests that $\mathrm{R}^{2}=2 \%$ is classified as a small effect, $\mathrm{R}^{2}=13 \%$ as a medium effect, and $\mathrm{R}^{2} \geq 26 \%$ as a large effect. Through Figure 1 and Table 2, it is possible to verify that the constructs, Forum Structure, and Forum Mediation, have high $\mathrm{R}^{2}$ (89\% and 84\%, respectively). These values demonstrate that the variables that comprise them significantly explain the phenomenon studied, confirming a quality adjustment of the structural model studied.

One of the ways to verify the discriminant validity is through the criteria of Fornell and Larcker (1981). Second Hair et al. (2018), discriminant validity ensures that the scale is sufficiently different from other similar concepts and so be distinct. This criterion is obtained by comparing the square roots of the AVE values of each construct with the correlations between the constructs (or latent variables). Thus, the square roots of the AVEs must be greater than the correlations between the constructs. Analyzing Table 5, it is possible to prove the Discriminating Validity between the constructs, that is, the Forum Structure and Forum Mediation constructs are measuring different concepts. At the same time, they give rise to the Quality Perception of Online Discussion Forums (QPODF) construct, as shown in Figure 1.

Table 5. Discriminant validity of the measurement model of the Quality Perception of Online Discussion Forums

\begin{tabular}{lll}
\hline Constructs & Structure Forums & Mediation Forums \\
\hline Structure of Forums & $\mathbf{0 . 8 5 *}$ & - \\
Forums mediation & 0.73 & $\mathbf{0 . 9 1}$ \\
\hline
\end{tabular}

Note: * Bold values (diagonal) is the square root of the AVEs, the other value is the Pearson correlation between the two constructs.

Source: Research data. 
After carrying out the tests above, it was found a good adjustment of the measurement model and, consequently, the validation of the QPODF scale. In this sense, it is also possible to say that QPODF is a second-order construct, being better understood and explained by two first-order constructs (Forum Structure and Forum Mediation). It is worth mentioning the correct choice of the oblique rotation method in the Exploratory Factor Analysis, as it is possible to see in Table 3 the strong positive correlation $(r=0.73)$ between the two constructs.

\section{COMPLEMENTARY DISCUSSION OF RESULTS}

The research results will be discussed from two perspectives. First, an analysis is made from a theoretical perspective, and secondly, a reflection is given on the psychometric assumptions in relation to the construction and validation of scales. Regarding the theory, it was clear that several presuppositions help determine the quality of the Online Discussion Forums (ODF) (Nandi, Chang \& Balbo, 2009; McNamara \& Brown, 2008; McLoughlin \& Luca, 2000; Wozniak \& Silveira, 2004; Graham, et al., 2001). However, there has been no interest on the part of researchers to validate their proposals using robust quantitative models and techniques that provide a better understanding of this phenomenon. Therefore, the results of this work inaugurate a particularly exciting line of research, since it places the user of the forum, in this case, the student, as a central element of the ODF evaluation process. Also, the study demonstrated that the quality of the ODF is better understood from two dimensions: Forum Structure and Forum Mediation.

As for the psychometric assumptions, it is essential to note that the theoretical approach used to develop the scale, was adequately suited for the validation of the measurement model. Thus, the dimensionality of the QPODF construct underwent the scrutiny of multivariate analyzes to support the theory, possibility the scale's validation. The two factors identified proved to be consistent and accurate in assessing the quality of online forums. Also, The tests performed obtained robust results meeting the various criteria for scale validation, proposed by several researchers (Thielmann \& Hilbig, 2019; Pasquali, 2007; Nunnaly, 1978)

The results validate a new proposal for evaluating the forums based on the students' attitudes towards structure and mediation. These findings can potentially impact the quality of collaborative learning. In this way, managers can identify whether the teaching-learning tool ODF is underutilized. When using the scale, educators can verify that the forums have been well designed, planned, and organized. Mainly, to identify if the online instructors are interacting correctly with the students, either asking, introducing new concepts to the debate, responding quickly, providing feedback. Finally, developing good practices that encourage interaction and collaborative learning.

\section{FINAL CONSIDERATIONS AND SUGGESTIONS FOR FUTURE RESEARCH}

Online Discussion Forums (ODF) are essential tools in distance learning modalities. This work sought to present a new tool that makes it possible to evaluate the effective use of the forum. In this sense, the objective of the study was to develop a measurement scale that would assess the perceived quality of ODF from the students' perspective. The scale's validity was considered consistent and robust. The results of the factor analysis of this study confirm the theoretical assumptions of McNamara and Brown (2008) and Graham et al. (2001). Thus, the QPODF construct also proved to be a valid and accurate measure. The seven items of the proposed scale, have robust and significant factor loads. The tests of reliability and validity reinforced the accuracy of the instrument QPODF. The scale items were theoretically consistent, the two factors obtained (Forum Structure and Forum Mediation) are in line with the theoretical basis of McNamara and Brown (2008) and Graham et al. (2001).

Despite the good QPODF indicators presented in this work, future studies must be carried out. It is suggested that in new investigations, other scales should be developed using different theoretical bases (Mazzolini \& Maddison, 2007; Wozniak \& Silveira, 2004; Knowlton, 2001; McLoughlin \& Luca, 2000). With this, it is possible to carry out comparative tests between the QPODF scale and the new scales. It is also recommended that further research propose other items on the QPODF scale, further refining the measurement instrument. Finally, it is suggested that the QPODF construct be integrated into other structural models. The construct must be tested as an antecedent of different constructs, such as, for example, school performance, student satisfaction, or perceived quality of the course. 
Finally, it is expected that the work will contribute to the academy by increasing the scope of works involving this theme. Another perspective for a user on the QPODF scale is its utility as an educational management tool. In this sense, it can be used by several courses aimed at distance education. That makes it possible to check if your forums are adequate. Furthermore, verifying some fundamental principles for a better evaluation of students. As a final result, it is expected that supervisors and tutors when using this new tool (QPODF), can contribute to the construction of collaborative knowledge in an online environment that makes use of the discussion forums

\section{BIODATA and CONTACT ADDRESSES of AUTHORS}

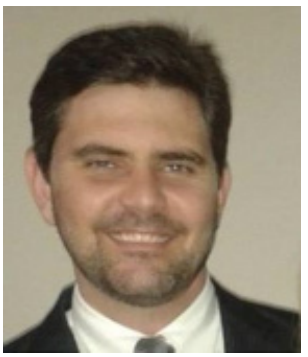

Alessandro Silva de OLIVEIRA is a Doctor in Administration from UNINOVESP (2016). Master in Administration Science from the Federal University of Lavras (2010). Degree in Business Administration from Instituto Presbiteriano Gammon (2002). He has a Lato Sensu Specialization in Micro and Small Business Management, Agribusiness Management and in Ecotourism: Interpretation and Planning of Activities in Natural Ambient. He is also a specialist in Planning, Implementation and Management of Distance Education from Federal University Fluminense. He is currently an Adjunct Professor at the Federal University of Mato Grosso do Sul. He is presently developing research on organic food consumption and consumer behavior using structural equation modeling.

Alessandro Silva de OLIVEIRA

Department of Administration

Address: Universidade Federal de Mato Grosso do Sul

Câmpus de Chapadao do Sul, Rod MS 306, Km 105, CXP 112

Chapadao do Sul/MS, Brazil. CEP 79560-000

Phone: +55 (67) 3562-6300

E-mail: alessandro.oliveira@ufms.br

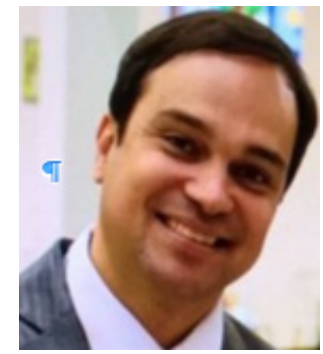

Dr. Matheus Alberto Rodrigues SILVA gained his PH.D. in administration at September, 2016. Professor Matheus Alberto Rodrigues Silva teaches administration at the Federal Institute of Sao Paulo. He researches, teaches, and advises corporations on branding, retail and customer experience. He is also a professor of MBA courses in marketing in Brazil. In addition, he has published relevant papers in Brazilian and European journals.

Matheus Alberto Rodrigues SILVA Federal Institute of Sao Paulo

Address: R. Antônio Fogaca de Almeida,

200 - Jardim America, Jacareí - SP, Postal code: 12322-030, Brazil.

Phone: +55 (16) 981210791

E-mail: matheus.rodrigues@ifsp.edu.br

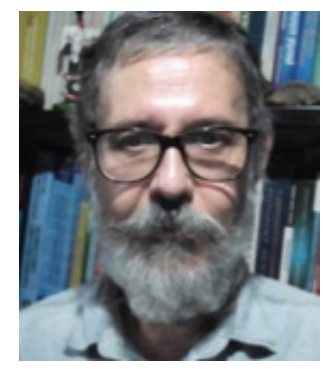

Dirceu da SILVA holds a degree in Physic at University of Sao Paulo (1981), master degree in Physic at University of Sao Paulo (1989) and Ph.D in Education at University of Sao Paulo (1995). Has experience in Administration, focusing on Business Administration, environment and sustainability and production management on the following subjects: numeric and statistics methods and multivariate data analysis. $\mathrm{He}$ is professor at University of Campinas (UNICAMP). 
Dirceu da SILVA

Department of Cultural Practices

Address: 801 Rua Bertrand Russel

Campinas State University, 13083-865, Campinas, Brasil

Phone: + 5519 (19) 3521-5553

E-mail: dirceu@unicamp.br

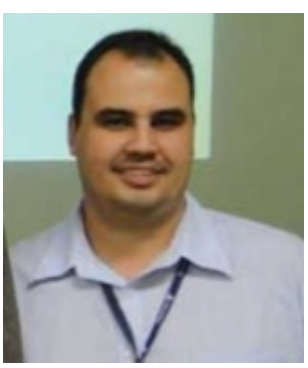

Richardson Coimbra BORGES is Professor of Finance and Statistics at the Federal University of Mato Grosso do Sul, campus of Paranaíba. PhD in Administration from the Federal University of Lavras - UFLA, in the Business Management, Economics and Markets concentration area, having defended his thesis in August 2015. His areas of academic interest are Economics, Finance, Accounting, Statistics, Investment Management and Cryptoactives. He works with the Data Envelopment Analysis, Factor Analysis, Structural Equations, Geostatistics and Multivariate Analysis methodologies.

\section{Richardson Coimbra BORGES}

Department of Administration

Address: Federal University of Mato Grosso do Sul, 79500-000,

Paranaíba, Brazil

Phone: +55 (67) 3369-0162

E-mail: richardson.borges@ufms.br

\section{REFERENCES}

Alghamdi, A. (2013). Pedagogical implications of using discussion board to improve student learning in higher education. Higher Education Studies, 3(5), 68-80.

AlJeraisy, M. N., Mohammad, H., Fayyoumi, A., and Alrashideh, W. (2015). Web 2.0 in education: The impact of discussion board on student performance and satisfaction. The Turkish On-line Journal of Educational Technology, 14(2), 247-259.

Alzahrani, M. G. (2017). The Effect of Using On-line Discussion Forums on Students' Learning. Turkish On-line Journal of Educational Technology-TOJET, 16(1), 164-176.

Anderson, J., \& Gerbin, D. (1988). Structural equation modeling in practice: a review and recommended two-step approach. Psychological Bulletin, 103(3), 411-423.

Andresen, M. A. (2009). Asynchronous discussion forums: Success factors, outcomes, assessments, and limitations. Educational Technology and Society, 12(1), 249-257.

Aranha, F., \& Zambaldi, F. (2008). Analise fatorial em administracao. Cengage Learning.

Biagiotti, L. C. B. (2005). Conhecendo e aplicando rubricas em avaliacôes. In Congresso Brasileiro de Educacao a Distância. 01-09.

Biondo, F. P. (2018). Papéis de professor e de aluno em foruns on-line de língua portuguesa. Acta Scientiarum. Language and Culture, $40(1)$.

Blackmon, S. J. (2012). Outcomes of chat and discussion board use in on-line learning: A research synthesis. Journal of Educators On-line, 9(2).

Brito, J. A., Melo Filho, I. J., Carvalho, R. S., Melo, R. M., \& Gomes, A. S. (2011). Interfaces colaborativas para atividades assíncronas em forum de discussao. In Anais do Simposio Brasileiro de Informatica na Educacao. 1(1).

Brookfield, S., \& Preskill, S. (1999). Discussion as a way of teaching: Tools and techniques for university teachers. McGraw-Hill Education. 
Brooks, C. D., \& Jeong, A. (2006). Effects of pre-structuring discussion threads on group interaction and group performance in computer-supported collaborative argumentation. Distance Education, 27(3), 371-390.

Cacheiro-Gonzalez, M. L., Medina-Rivilla, A., Dominguez-Garrido, M. C., \& Medina-Dominguez, M. (2019). The Learning Platform in Distance Higher Education: Student's Perceptions. Turkish Online Journal of Distance Education, 20(1), 71-95.

Cameron, L. (2009). Assessing on-line discussions and forums. In: Proceedings of the 2009 European LAMS and Learning Design Conference: Opening up Learning Design. Sydney.

Chang, C. K., Chen, G. D., \& Hsu, C. K. (2011). Providing adequate interactions in on-line discussion forums using few teaching assistants. The Turkish On-line Journal of Educational Technology, 10(3), $193-202$.

Cohen, J. (1988). Statistical Power Analysis for the Behavioral Sciences. 2th ed. New York: Psychology Press.

Conrad, S. S., \& Dabbagh, N. (2018). Student and instructors perceptions of helpful feedback for asynchronous online learning: What students want from instructor feedback. In Innovative applications of online pedagogy and course design (pp. 177-201). IGI Global.

Creswell, J. W., \& Clark, V. L. P. (2017). Designing and conducting mixed methods research. Sage Publications, California.

Damasio, B. F. (2012). Uso da analise fatorial exploratoria em psicologia. Aval. psicol., Itatiba, 11(2).

Davis, P. (2012). On-line forums: The forgotten social media platform. The Playbook, 10.

Dennen, V. P. (2005). From message posting to learning dialogues: Factors affecting learner participation in asynchronous discussion. Distance Education, 26(1), 127-148.

Dringus, L. P., \& Ellis, T. (2005). Using data mining as a strategy for assessing asynchronous discussion forums. Computers and Education, 45(1), 141-160.

Dunlap, J. C. (2005). Workload reduction in on-line course: Getting some shuteye. Performance Improvement, $44(5)$.

Edelstein, S., \& Edwards, J. (2002). If you build it, they will come: Building learning communities through threaded discussions. On-line Journal of Distance Learning Administration, 5(1).

Ellis, R. (2005). Principles of instructed language learning. System, 33(2), 209-224.

Feldman, R., \& Sanger, J. (2007). The Text Mining Handbook: Advanced Approaches in Analyzing Unstructured Data. Cambridge, MA: Cambridge University Press.

Field, A. (2017). Discovering statistics using IBM SPSS statistics. 5th ed. SAGE Publications Ltd.

Fornell, C., \& Larcker, D. F. (1981). Evaluating structural equation models with unobservable variables and measurement error. Journal of Marketing Research, 18, 39-50.

Gaytan, J., \& Mcewen, B. C. (2007). Effective on-line instructional and assessment strategies. The American Journal of Distance Education, 21(3), 117-132.

Geer, R., \& Barnes, A. (2001). E-mail discussion and student learning outcomes: A case study. International Educational Journal, 2(4).

Gefen, D., \& Straub, D. (2005). A practical guide to factorial validity using PLS-Graph: Tutorial and annotated example. Communications of the Association for Information systems, v. 16(1), 5.

Graham, C., Cagiltay, K., Lim, B. R., Craner, J., \& Duffy, T. M. (2001). Seven principles of effective teaching. The Technology Source, 30(5), 50.

Hair, J. F., Black, W. C., Babin, B. J., \& Anderson, R. E. (2018), Multivariate Data Analysis. 8th ed., Cengage Learning EMEA.

Hair, J. F., Hult, G. T. M., Ringle, C., \& Sarstedt, M. (2017), A primer on partial least squares structural equation modeling (PLS-SEM). 2th ed. Sage Publications. 
Hair, J. F., Ringle, C. M., \& Sarstedt, M. (2011). PLS-SEM: Indeed a silver bullet. Journal of Marketing theory and Practice, 19(2),139-152.

Hair, J. F., Sarstedt, M., Ringle, C. M. \& Mena, J. A. (2012). An assessment of the use of partial least squares structural equation modeling in marketing research. Journal of the Academy of Marketing Science, 40(3), 414-433.

Hulkari, K., \& Mahlamäki-Kultanen, S. (2008). Reflection through web discussions: Assessing nursing students' work-based learning. Journal of Workplace Learning, 20(3), 157-164.

Jacob, S. M. (2012). Mathematical achievement and critical thinking skills in asynchronous discussion forums. Procedia - Social and Behavioral Sciences, 31, 800-804.

Klemm, W. R. (2000). What's Wrong With On-line Discussions - And How To Fix It., In Gordon Davies and Charles B. Owen. WebNet, AACE, 335-340.

Knowlton, D. (2001). Promoting durable knowledge constructions through on-line discussion. In Proceedings of the Annual Mid-South Instructional Technology Conference. 6th ed., Murfreesboro,Tennessee.

Koole, S., Vervaeke, S., Cosyn, J., \& Bruyn, H. (2014). Exploring the relation between on-line case-based discussions and learning outcomes in dental education. Journal of Dental Education, 78(11), 15521557.

Kratochwill, S. (2009). Avaliacao da aprendizagem em uma perspectiva dialogica a partir do forum on-line. In Aprendizagem em ambientes virtuais e educacao a distância. Porto Alegre: Mediacao, 135-168.

Lee, S. J. (2008). Designing a Peer Rating System for Asynchronous discussion. Association for Educational Communications and Technology: Estados Unidos, 413-417.

Malhotra, N. K. (2020). Marketing research: An Applied Orientation. 8th ed. Pearson Education.

Malhotra, N., Nunan, D. \& Birks, D.F. (2017), Marketing Research: An Applied Approach, 5th ed., New York: Pearson.

Mazzolini, M., \& Maddison, S. (2007). When to jump in: The role of the instructor in on-line discussion forums. Computers and Education, 49(2), 193-213.

McLoughlin, C., \& Luca, J. (2000). Cognitive engagement and higher order thinking through computer conferencing: We know why but do we know how? Flexible futures in tertiary teaching: Proceedings of the 9rd Annual Teaching Learning Forum, 2-4.

McNamara, J., \& Brown, C. (2008). Assessment of collaborative learning in on-line discussions. ATN Assessment, 1(1).

McNamara, J., \& Brown, C. (2009). Assessment of on-line discussion in work-integrated learning. CampusWide Information Systems, 26(5), 413-423.

McNamara, J., \& Burton, K. (2009). Assessment of on-line discussion forums for law students. Journal of University Teaching and Learning Practice, 6(2), 6.

Nandi, D., Chang, S., \& Balbo, S. (2009). A conceptual framework for assessing interaction quality in online discussion forums. Same places, different spaces. Proceedings ascilite Auckland, 665-673.

Nelson, M., Bhagyavati, M. G., Settle, A., Shaffer, D., \& Watts, J. (2005). On-line teaching practices (both best and worst). Panel discussion. Journal of Computing Sciences in Colleges, 21(2). 14.

Nunes, B. P., Kawase, R., Fetahu, B., Casanova, M. A., \& de Campos, G. H. B. (2014). Educational forums at a glance: Topic extraction and selection. In International Conference on Web Information Systems Engineering. 351-364.

Nunnaly, J. C. (1978). Psychometric theory. New York: McGraw-Hill Book.

Parks-Stamm, E. J., Zafonte, M., \& Palenque, S. M. (2017). The effects of instructor participation and class size on student participation in an online class discussion forum. British Journal of Educational Technology, 48(6), 1250-1259. 
Pasquali, L. (2007). Validade dos testes psicologicos: sera possível reencontrar o caminho. Psicologia: Teoria e Pesquisa, 23, 99-107.

Revill, G., \& Terrell, I. (2005). Learning in the workplace: A new degree on-line. Innovations in Education and Teaching International, 42(3), 231-245.

Ringle, C. M., Wende, S., \& Will, S. (2005). SmartPLS (versao 2.0 M3 Beta) [Software]. Hamburg: SmartPLS.

Ringle, C. M. Silva, D., \& Bido, D. S. (2014). Modelagem de equacóes estruturais com utilizacao do SmartPLS. REMark, 13(2), 54.

Salmon, G. (2002). E-tivities: The Key to Active On-line Learning. RoutledgeFalmer, London.

Sanchez, L. P. (2005). El foro virtual como espacio educativo: propuestas didacticas para su uso. Verista Quaderns Digitals Net, 40,1-18.

Shana, Z. (2009). Learning with technology: Using discussion forums to augment a traditional-style class. Journal of Educational Technology and Society, 12(3), 214-228.

Shaul, M. (2007). Assessing on-line discussion forum participation. International Journal of Information and Communication Technology Education, 3(3), 39-46.

Silva, M. (2003). Educacao on-line: teorias, praticas, legislacao, formacao corporativa. Sao Paulo: Edicóes Loyola.

Souza, V. F., \& Perry, G. T. (2019). Mineracao de Texto em Moocs: Analise da Relevância Tematica de Postagens em Foruns de Discussao. RENOTE-Revista Novas Tecnologias na Educacao, 17(3), 204213.

Straub, D., Boudreau, M. C., \& Gefen, D. (2004). Validation guidelines for IS positivista research. Communications of the Association for Information systems, 13(1), 24.

Tabachnick, B., \& Fidell, L. (2013). Using multivariate analysis. 6rd. Pearson Education.

Tan, C. K. (2006). The implementation of an online discussion board for collaborative learning. Online teaching and learning in ELT, 111-131.

Tan, K. E. (2017). Using online discussion forums to support learning of paraphrasing. British Journal of Educational Technology, 48(6), 1239-1249.

Thielmann, I., \& Hilbig, B. E. (2019). Nomological consistency: A comprehensive test of the equivalence of different trait indicators for the same constructs. Journal of personality, 87(3), 715-730.

Ting, L., Mansor, W. F. A. W., Zakaria, M. H., \& Deris, F. D. (2013). On-line Discussion Behavior Within Collaborative Learning Via E-Forum. Jurnal Tekenologi (Social Sciences), Skudai (Malasia), 65(2), 67-74.

Vonderwell, S., Liang, X., \& Alderman, K. (2007). Asynchronous discussions and assessment in on-line learning. Journal of Research on Technology in Education, 39(3), 309-328.

Wei, H. C., Peng, H., \& Chou, C. (2015). Can more interactivity improve learning achievement in an online course? Effects of college students' perception and actual use of a course-management system on their learning achievement. Computers and Education, 83, 10-21.

Wozniak, H., \& Silveira, S. (2004). On-line discussions: Promoting effective student to student interaction. In R. Atkinson, C. McBeath, D., Jonas-Dwyer and R. Phillips (Eds), Beyond the comfort zone: Proceedings of the 21st ASCILTIE Conference, Perth, 5-8 December. 956-960.

Xia, J., Fielder, J., \& Siragusa, L. (2013). Achieving better peer interaction in on-line discussion forums: A reflective practitioner case study. Issues in Educational Research, 23(1), 97-113. 